\title{
A Study on Assessment of Attitude and its Impact on Practice in Patients with Diabetes Mellitus
}

\author{
Potha Amulya Reddy 1,*, K Saravanan², A Madhukar ${ }^{3}$ \\ ${ }^{1}$ Department of Pharmacy Practice, St. Pauls College of Pharmacy, Nagarjuna Sagar Road, Turkayamja, Hyderabad, Telangana, INDIA. \\ 2Department of Pharmacy, Annamalai University, Annamalainagar, Tamil Nadu, INDIA. \\ ${ }^{3}$ Department of Pharmaceutical Analysis and Quality Assurance, MRM College of Pharmacy, Bongloor, Telangana, INDIA.
}

\begin{abstract}
Background: Diabetes Mellitus (DM) is a group of metabolic disorders characterized by hyperglycaemia and is associated with abnormalities in carbohydrate, fat, and protein metabolism, which results in chronic complications, comprising microvascular, macro vascular, and neuropathic disorders. Key complications of diabetes are avoidable by proper control on their blood glucose levels and this needs training of the person with diabetes in handling their condition. The aim of the study was to analyse the Attitude and its influence on Practice of patients with Diabetes. Methods: Patients of either sex with $\geq 1$-year history of diabetes and who were willing to give the consent were involved in the study. Patients of either sex with $<1$ year history of Diabetes Mellitus, Pregnant/lactating women and patients who are not ready to give the consent were excluded from the study. Attitude and practice was assessed by means of questionnaire which was closed ended consisting of 8 Attitude and 7 Practice questions. 200 patients were analysed in the study. Results: When Attitude and Practice scores were compared, results showed that despite having good attitude
\end{abstract}

on Diabetes, many patients did not have good practice towards Diabetes in many terms which indicates that there is an increased need for creating awareness on the importance of Attitude and Practice with regards to the disease, that helps in appropriate management and prevention of its complications. Conclusion: The study directs the significant evidence on the role of pharmacists in providing Diabetes care, however the provision of such services remains inconsistent.

Key words: Diabetes Mellitus, Attitude, Practice, Complications, Pharmacist.

\section{Correspondence}

Prof. P Amulya Reddy,

Assistant Professor, Department of Pharmacy Practice, St. Pauls College of Pharmacy, Nagarjuna Sagar Road, Turkayamja, Hyderabad-501510, Telangana, INDIA.

Email id: amulyareddy485@gmail.com

DOI: 10.5530/jyp.2021.13.96

\section{INTRODUCTION}

Diabetes Mellitus (DM) is a group of metabolic disorders characterized by hyperglycaemia and is associated with abnormalities in carbohydrate, fat, and protein metabolism, which results in chronic complications, comprising microvascular, macro vascular, and neuropathic disorders. World Health Organization's (WHO) latest 2016 data says that worldwide 422 million adults are expected to be living with DM and is anticipated to increase by twofold $2030 .{ }^{1}$ In a study conducted to estimate the Global Prevalence of DM, India was estimated to have the highest number of cases (79.4 million) of DM by 2030, compared to other countries like China, US, Indonesia, Pakistan, Brazil, Bangladesh, Japan, Egypt and Philippines. $^{2}$

Uncontrolled Diabetes or poor glycaemic control leads to chronic hyperglycaemia, thereby causing the development of long-term microvascular, macro-vascular, and neuropathic complications. American Diabetes Association suggests the target for long-term glycaemic control in patients with diabetes is glycated haemoglobin $\mathrm{A}_{1 \mathrm{c}}$ $\left(\mathrm{HbA}_{1 \mathrm{c}}\right)$ value of less than $7 \%$. Studies showed that significant reduction in the mortality and morbidity occurs with the improved glycaemic control. ${ }^{3}$ Key complications of diabetes are avoidable by proper control on their blood glucose levels and this needs training of the person with diabetes in handling their condition. Literature confirms that patient tutoring that improves their Attitude and Practice greatly reduces the complications of diabetes and helps in its management. There are studies that showed individuals who are educated in their diabetes self-care achieved better diabetic control. A good attitude towards DM complications improves Practice in Diabetes patients that helps them change any harmful dietary and lifestyle habits. ${ }^{4}$ During the past 30 years, there has been notable modification in way of life of people largely resulting in diminished physical activity and unhealthy eating habits. These changes have had a significant negative impact on the health of the society and are considered to be accountable for the epidemic of noncommunicable diseases and their complications. Lifestyle modifications like cessation of smoking and alcohol, regular exercise, dietary practices assist in regulating blood sugar in diabetic patients. ${ }^{5}$

Participation of patients is very essential in controlling diabetes mellitus as medications alone aren't adequate to manage the disease without different non pharmacological measures. ${ }^{6}$ Pharmacists represent the third largest health profession in the world after doctors and nurses and most of them work in the community with a smaller proportion in hospital pharmacy, academia, industry, and research. Community pharmacies provide a range of products (in respect to diabetes medication, blood glucose meters and testing strips, needles and swabs, dietary supplements) and services. ${ }^{7}$ Practicing effective behaviour management of the diet in DM patients can result in improved medical outcomes like reduction of $\mathrm{HbAlc}$ value, reduced weight which would in turn reduce the complications of DM. ${ }^{8}$

There is a need to assess Attitude and Practice of patients with diabetes in order to aid in future development of control programs and techniques for effective health education and patients counselling. This helps in ensuring that each patient with diabetes has sufficient information and are motivated to lead a better life. Hence, this study was intended 
to evaluate the Attitude and its influence on Practice of patients with Diabetes.

Attitude is a way of being, a position. This is an intermediate variable between the situation and the response to this situation. Attitudes are not directly observable as are practices, thus it is a good idea to assess them. Practices or behaviours are the observable actions of an individual in response to a stimulus.

The aim of the study was to assess the Attitude and its influence on Practice of patients with Diabetes.

\section{MATERIALS AND METHODS}

Prior approval from Independent ethics committee was taken. All the patients were thoroughly explained about the study in native language through informed consent form.

\section{Study Design and Data Collection}

This was a prospective observational study conducted from August 2019 to January 2021 in Yashoda Hospital, Hyderabad. Patients of either sex with $\geq 1$-year history of diabetes and who were willing to give the consent were included in the study. Patients of either sex with $<1$ year history of DM, Pregnant/lactating women and patients who are not willing to give the consent were excluded from the study. A Patient data collection form was designed to collect the demographic and laboratory details. An informed consent form consisting of the study information was prepared in the regional language (Figure 4).

\section{Data Analysis}

After obtaining the consent from the patients through the informed consent form, information was gathered into Patient data collection form that contained the socio demographic details of the patient like age, sex, educational qualification, occupation, family annual income, social and family history and also data on comorbid diseases. Data on Blood glucose levels (FBS, PPBS) and $\mathrm{HbA}_{1 \mathrm{c}}$ was also obtained and assessed. Attitude and Practice questionnaire was administered to the patients and assessed. The questionnaire was closed ended consisting of 8 Attitude and 7 Practice questions with only two Options-Yes or No, where option yes was considered correct and no was considered incorrect. Each correct answer was given a score 1 and the incorrect answer was given a score 0 .

The questions on Attitude cover information that can assess the patients' attitude towards regular monitoring of body weight, blood glucose level, exercise following a planned diet and taking medications regularly. The questions on Practice cover information on the patients' contribution towards management of DM in terms of following a planned diet, exercise, regular monitoring of weight and glucose levels.

\section{Statistical Analysis}

Descriptive and inferential statistical analysis was carried out in this study. Data's were mentioned in mean (SD) values and categorical variables were presented in percentage. Microsoft word and excel were used to generate graphs and tables.

\section{RESULTS}

\section{Socio demographic Characteristics of the patients}

A total of 200 patients were analysed in the study where 108 (54\%) were males and $92(46 \%)$ were females.

The average age of the patients was 58.5 years with majority being $51-70$ years $(73.5 \%)$ of age. Out of 200 patients, 59 (29.5\%) completed their Intermediate. Patients qualified with Primary and Graduation were approximately equal in the study i.e., 47 (23.5\%) and $46(23 \%)$ respectively. About 79 (39.5\%) patients were private employees, 68 (34\%) were House wives and $25(12.5 \%)$ were illiterates. Table 1 depicts the demographic characteristics of the patients.
173 (86.5\%) had a family income of more than INR.200000 per annum and 27 (13.5\%) had less than INR 200000 per annum. 178 (89\%) patients were non-smokers and rest 22(11\%) smoked at least 05 cigarettes a day. $149(74.5 \%)$ were non-alcoholic in the study and $51(25.5 \%)$ had a history of alcohol consumption.

$182(91 \%)$ patients didn't have any family history whereas $18(9 \%)$ had either history of DM, HTN or both. 108 (54\%) patients had history of Diabetes since last 6-10 years and 78(39\%)patients had 1-5 years' history of Diabetes. A very few patients had 11-20 years' history of Diabetes, i.e., $14(7 \%)$.

Figure 1 shows that the mean FBS was $135.09 \pm 28.15 \mathrm{mg} / \mathrm{dL}$, with majority $(20.5 \%)$ of the patients having it between $131-140 \mathrm{mg} / \mathrm{dL}$, followed by $12.5 \%$ of patients having it between $91-100 \mathrm{mg} / \mathrm{dL}$ and $161-170 \mathrm{mg} / \mathrm{dL}$. Figure 2 shows that the mean PPBS was $184.92 \pm 17.23 \mathrm{mg} / \mathrm{dL}$, with majority $(52 \%)$ of the patients having it between $181-200 \mathrm{mg} / \mathrm{dL}$, followed by $28.5 \%$ of patients having it between 161-180 mg/dL. Figure 3 shows that the mean $\mathrm{HbA}_{1} \mathrm{C}$ was $8.29 \pm 0.85 \%$ with majority (27.5\%) of the patients having it between $8.6-9 \%$, followed by $20.5 \%$ having it between $7.6-8 \%$.

\section{Assessment of Attitude and Practice Scores}

Table 2 and Table 3 show the Scores of Attitudes and Practices of the patients respectively. There was $92 \%$ correct response for the $1^{\text {st }}$ question of Attitude where majority (137) of them were in the age group of 51-70 years, followed by $90.5 \%$ for the $2^{\text {nd }}$ question, where again the majority of them were of $51-70$ years, followed by $73.5 \%$ for the $7^{\text {th }}$ question where majority of them were of 61-70 years, followed by $35.5 \%$ for the $5^{\text {th }}$ question within the age of 51-60 years, followed by $30 \%$ for the $8^{\text {th }}$ question within the age group of 51-60 years, followed by $29 \%$ for the $6^{\text {th }}$ question of 51-70 years, followed by $20 \%$ for the $4^{\text {th }}$ question in the age group of $61-70$ years and $14.5 \%$ for the $3^{\text {rd }}$ question in the age

Table 1: Socio demographic Characteristics of the patients.

\begin{tabular}{cccc}
\hline Age (years) & N (\%) & Family Annual Income & N (\%) \\
\hline $31-40$ & $2(1)$ & $<200000$ & $27(13.5)$ \\
$41-50$ & $42(21)$ & $>200000$ & $173(86.5)$ \\
$51-60$ & $74(37)$ & H/O Smoking & $\mathrm{N}(\%)$ \\
$61-70$ & $73(36.5)$ & 1 pack/day & $1(0.5)$ \\
$71-80$ & $9(4.5)$ & $1-2$ packs/day & $13(6.5)$ \\
GENDER & $\mathrm{N}(\%)$ & $3-4$ packs/day & $1(0.5)$ \\
F & $92(46)$ & 5 packs/day & $2(1)$ \\
M & $108(54)$ & $5-6$ cigarettes /day & $5(2.5)$ \\
Qualification & $\mathrm{N}(\%)$ & Non smokers & $178(89)$ \\
Graduate & $46(23)$ & H/O Alcohol & $\mathrm{N}(\%)$ \\
& & Consumption & \\
High School & $23(11.5)$ & Daily More Than Once & $1(0.5)$ \\
Illiterate & $25(12.5)$ & Daily Once & $3(1.5)$ \\
Intermediate & $59(29.5)$ & Occasionally & $30(15)$ \\
Primary & $47(23.5)$ & Weekly Once & $17(8.5)$ \\
Occupation & $\mathrm{N}(\%)$ & Non Alcoholic & $149(74.5)$ \\
Farmer & $16(8)$ & Family History & $\mathrm{N}(\%)$ \\
Govt. employee & $11(5.5)$ & DM & $5(2.5)$ \\
House Wife & $68(34)$ & DM and HTN & $8(4)$ \\
Private employee & $79(39.5)$ & HTN & $5(2.5)$ \\
Retired & $26(13)$ & No Family history & $182(91)$ \\
\hline
\end{tabular}




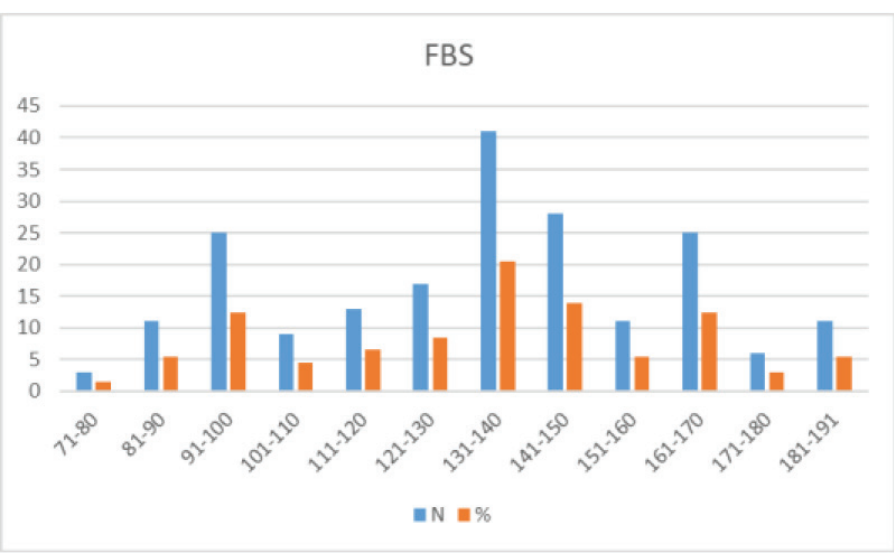

Figure 1: Fasting Blood Glucose Levels (mg/dL).

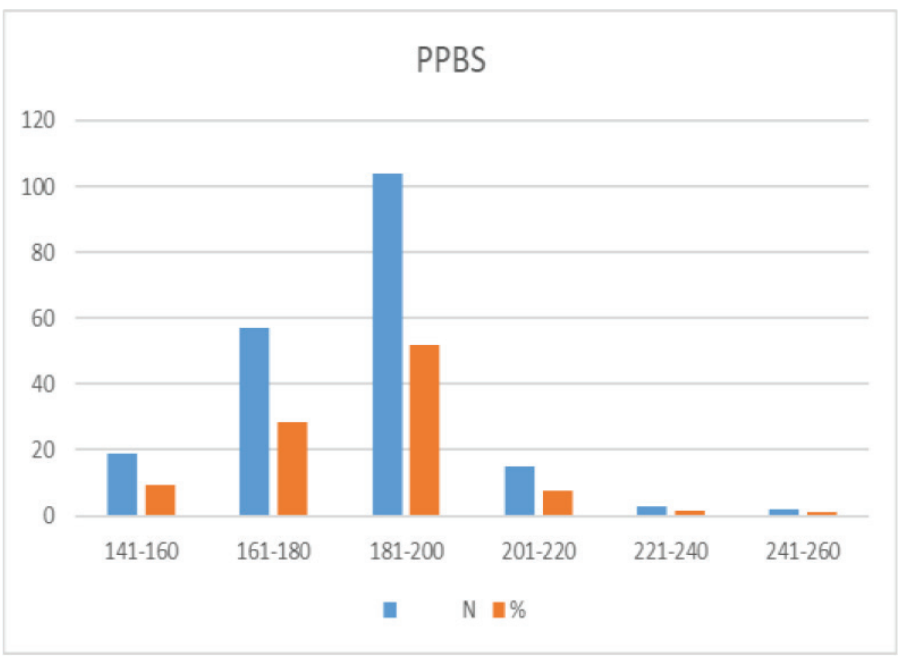

Figure 2: Post Prandial Blood Glucose Levels (mg/dL).

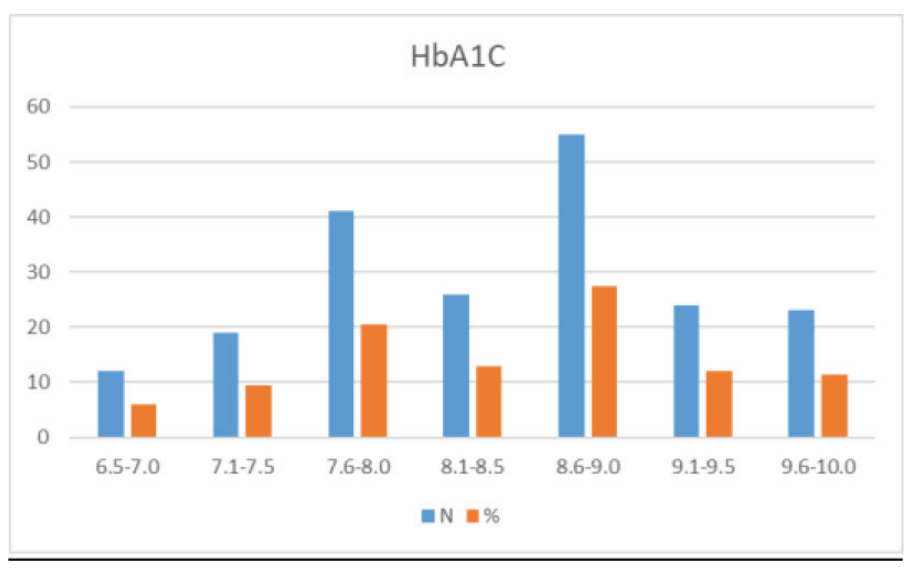

Figure 3: $\mathrm{HbA}_{1} \mathrm{C}$ Levels (\%).

group of 41-50 years. The common characteristic was majority of them were with a 6-10 years' history of diabetes and their qualification was Intermediate/graduates.

A 9 of 200 patients achieved the highest score which was 6 of 8 and 22 scored the lowest which was 2 of 8 in Attitude.
Table 2: Scores of Attitudes.

\begin{tabular}{lc}
\multicolumn{1}{c}{ Attitude Question (YES=1, NO=0) } & $\begin{array}{l}\text { \% correct } \\
\text { response }\end{array}$ \\
\hline $\begin{array}{l}\text { 1. Do you think that following a controlled (low sugar) and } \\
\text { planned diet will help improve diabetes? }\end{array}$ & 92 \\
2. Do you think that regular exercise can help improve \\
diabetes? \\
$\begin{array}{l}\text { 3. Do you think missing doses of your diabetic medication } \\
\text { will have a negative effect on your disease control? }\end{array}$ \\
$\begin{array}{l}\text { 4. Do you think you should keep in touch with your } \\
\text { physician? }\end{array}$ \\
$\begin{array}{l}\text { 5. Do you think that keeping the blood sugar close to normal } \\
\text { can help to prevent the complications of diabetes? } \\
\text { 6. Do you think that once diabetes is controlled, eating } \\
\text { restrictions are still required? }\end{array}$ \\
$\begin{array}{l}\text { 7. Do you think that people with diabetes should control their } \\
\text { weight? }\end{array}$ \\
$\begin{array}{l}\text { 8. Do you think that diabetics should not skip their } \\
\text { medication even when the blood glucose is not too high? }\end{array}$ \\
\hline
\end{tabular}

Table 3: Scores of Practices.

\begin{tabular}{lc}
\hline \multicolumn{1}{|c}{ Practice Question (YES=1, NO=0) } & $\begin{array}{c}\text { \% correct } \\
\text { response }\end{array}$ \\
\hline 1. Do you exercise regularly? & 26.5 \\
2. Do you check your feet regularly and go for regular eye check-up? & 0 \\
3. Do you follow a controlled (low sugar) and planned diet? & 73 \\
4. Do you keep in touch with your physician? & 0 \\
5. Do you regularly monitor your body weight? & 5.5 \\
6. Do you regularly monitor your blood glucose levels? & 42.5 \\
7. Do you take your medicines regularly? & 84.5 \\
\hline
\end{tabular}

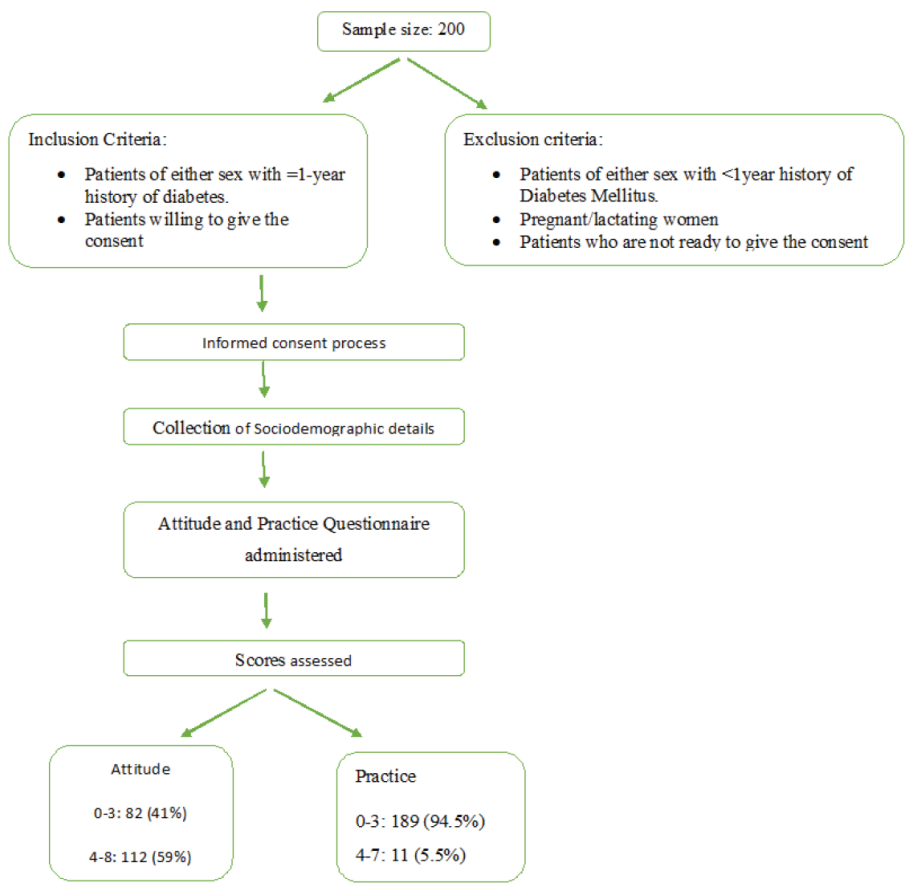

Figure 4: Layout of study design and its results. 
There was $84.5 \%$ correct response for the $7^{\text {th }}$ question of Practice where majority of them were in the age group of 51-70 years, followed by $73 \%$ for $3^{\text {rd }}$ question where again the majority of them were in the age group of $51-70$ years, followed by $42.5 \%$ for $6^{\text {th }}$ question where majority of them were in the age group of 51-60 years, followed by $26.5 \%$ for $1^{\text {st }}$ question where majority of them were in the age group of $61-70$ years, and 5.5\% for $5^{\text {th }}$ question where majority of them were in the age group of 51-60 yrs. The common characteristic was majority of them were with a 6-10 years' history of diabetes and their qualification was Intermediate/graduates. There was $100 \%$ wrong response for the $2^{\text {nd }}$ and $4^{\text {th }}$ questions where majority of them were in the age group of 51-70years with a 6-10 years' history of diabetes and their qualification being Intermediate/graduates. An 11 of 200 patients achieved the highest score which was 4 of 7 and 4 scored the lowest which was 0 of 7 in Practice.

Of 200 patients, $169(84.5 \%)$ said that they took their medication regularly, however when assessed against their $\mathrm{HbA}_{1} \mathrm{C}$ levels, 159 (94\%) had their $\mathrm{HbA}_{1} \mathrm{C}$ levels above 7\%; 115 (68\%) had their $\mathrm{HbA}_{1} \mathrm{C}$ levels above $8 \%$ while only 10 patients had their $\mathrm{HbA}_{1} \mathrm{C}$ levels in the range of $6.5-7 \%$.

\section{DISCUSSION}

In a study conducted by Tejaswi et al., 94\% believed in controlled and planned diet which was closer to the findings in this study which was 92\%. ${ }^{[9]}$ When Attitude results from this study were compared with other such similar studies (Tejaswi et al., Bollu et al., Rathod et al.), variations were observed..$^{9-11}$ In this study, $90.5 \%$ of the patients had good attitude towards regular exercise, while only $50 \%, 36 \%$ and $73.68 \%$ had good attitude towards regular exercise in Tejaswi et al, Bollu et al., Rathod et al. studies respectively. In another study conducted by Shah et al., $70.16 \%$ monitored their blood glucose levels regularly which was very much alike to the results of the study done by Tejaswi et al., where $72 \%$ of the patients regularly monitored their blood glucose levels., ${ }^{912}$ These results were in contrary to the results of this study where only $42.5 \%$ monitored their blood glucose levels regularly.

In the present study, neither a single patient monitored their feet regularly nor did they go for regular eye check-up which was not at all a satisfactory finding and when compared to other study 55\% monitored their feet regularly and $41 \%$ went for regular eye check-up. ${ }^{9}$

When Attitude and Practice scores were compared, it showed that though majority (92\%) of them thought that they should follow a controlled, planned diet, only $73 \%$ made it a practice to follow a planned diet. Also, most $(90.5 \%)$ of them thought that regular exercise improves condition of Diabetes, however only $26.5 \%$ made it a Practice to regularly exercise. $73.5 \%$ of them thought that patients with Diabetes should control their body weight, yet only $5.5 \%$ had a Practice of regularly monitoring their body weight at home. Though many of the patients had good practice of taking medications regularly and following a planned diet, their $\mathrm{HbA1C}$ levels were higher than the acceptable range.

This showed that despite having good attitude towards Diabetes, many patients did not have good practice towards Diabetes in many terms.

\section{CONCLUSION}

Good Practice towards Diabetes is important along with good Attitude in its of DM, in achieving good glycaemic control and preventing its complications. This study showed that though patients had good attitude towards DM, their attitude did not significantly impact their practice in management of DM.

The study concludes that there is an increased need for creating awareness on the importance of Attitude and Practice towards
Diabetes, that helps in appropriate management and prevention of its complications. The study indicates the significant evidence on the role of pharmacists in providing Diabetes care, however the provision of such services remains inconsistent. Though the study cannot be generalised, the conclusions could help in developing possibilities of educational needs required for Diabetes patients.

Limitations of the study: The research was performed in only a single centre and the sample size was small (200). The study was dependent on the answers given by the patients and so there is no complete assurance of the response of patients to be correct.

\section{ACKNOWLEDGEMENT}

The authors wish to express their sincere gratitude to all the people who a participated and cooperated in the study.

\section{CONFLICT OF INTEREST}

The authors have no conflicts of interest.

\section{ABBREVIATIONS}

DM: Diabetes Mellitus; F: Female; FBS: Fasting Blood Sugar; HbA1C: Glycosylated Haemoglobin; HTN: Hypertension; INR: Indian Rupee; M: Male; PPBS: Post Prandial Blood Sugar; SD: Standard Deviation; WHO: World Health Organisation.

\section{REFERENCES}

1. Asmelash D, Abdu N, Tefera S, Baynes HW, Derbew C. Knowledge, attitude, and practice towards glycemic control and its associated factors among diabetes mellitus patients. J Diabetes Res. 2019;2019:Article ID 2593684. doi: 10.1155/2019/2593684, PMID 31089472

2. Wild SH, Roglic G, Green A, Sicree R, King H. Global prevalence of diabetes: estimates for the year 2000 and projections for 2030: response to Rathman and Giani. Diabetes Care. 2004;27(10):2560-70.

3. Asmelash D, Abdu N, Tefera S, Baynes HW, Derbew C. Knowledge, attitude, and practice towards glycemic control and its associated factors among diabetes mellitus patients. J Diabetes Res. 2019;2019:2593684. doi: 10.1155/2019/2593684, PMID 31089472.

4. Belsti Y, Akalu Y, Animut Y. Attitude, practice and its associated factors towards Diabetes complications among type 2 diabetic patients at Addis Zemen District Hospital, Northwest, Ethiopia. BMC Public Health. 2020;20(1):785. doi: 10.1186/ s12889-020-08953-6, PMID 32456637.

5. Jaiswal K, Moghe N, Mehta MC, et al. Knowledge, attitude and practices of type II diabetes mellitus patients in a tertiary care teaching institute of central India. J Diabetes Metab Disord Control. 2019;6(1):1-4.

6. Kant $R$, Thapliyal $V$. Knowledge attitude and practice of type 2 diabetic patients in a tertiary care teaching hospital in India. Integr Food Nutr Metab. 2015;2(1):131-5.

7. Dhandapani C, Sony S, Kumaran KA. Role of clinical pharmacist in the management of type II diabetes mellitus and its outcomes. Int J Pharm Teach Pract. 2014;5(3):977-83.

8. Hu X, Zhang Y, Lin S, Guo X, Yang D, Cai M, et al. Dietary knowledge, attitude and practice (KAP) among the family members of patients with type 2 diabetes mellitus (T2DM) and its influence on the KAP of T2DM patients. Diabetes Metab Syndr Obes. 2021;14:205-13. doi: 10.2147/DMSO.S290639, PMID 33488108.

9. Tejaswi DP, Dhakre DS, Reddy DP, Goyal DC. Evaluation of the knowledge, attitudes and practices of diabetic patients in a tertiary care hospital in Central India. Int J Med Res Rev. 2018;6(1):24-32. doi: 10.17511/ijmrr.2018.i01.05.

10. Bollu M, Nalluri KK, Prakash A, Lohith M, Venkataramarao N. Study of knowledge, attitude, and practice of general population of Guntur toward silent killer diseases: Hypertension and diabetes. Asian J Pharm Clin Res. 2015;8(4):74-8.

11. Rathod S, Kumar S, Rathod GB, Parmar P. Knowledge, attitude and practice (KAP) of general population of Vadodara towards diabetes mellitus. Int Arch Integr Med. 2018;5(4)

12. Shah VN, Kamdar PK, Shah N. Assessing the knowledge, attitudes and practice of type 2 diabetes among patients of Saurashtra region, Gujarat. Int J Diabetes Dev Ctries. 2009;29(3):118-22. doi: 10.4103/0973-3930.54288, PMID 20165648.

\footnotetext{
Article History: Received: 23-06-2021; Revised: 02-08-2021; Accepted: 10-10-2021.

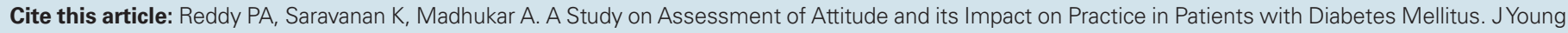
Pharm. 2021;13(4):396-9.
} 